\title{
Increasing Rainfall and Runoff in Alpine Mountainous Areas Can't Completely Eliminate Drought Driven by Temperature Rise
}

\section{Yu Deng}

Sichuan Agricultural University

\section{Zhifeng Guo}

Sichuan Agricultural University

Fuquan Ni (D645024674@qq.com )

Sichuan Agricultural University

\section{Lianqing Xue}

Hohai University

\section{Yiping Wu}

Xi'an Jiaotong University

\section{Ouping Deng}

Sichuan Agricultural University

\section{Man Zhou}

Sichuan Agricultural University

Jian Hu

Sichuan Agricultural University

\section{Ying Zhang}

Sichuan Agricultural University

\section{Ruihan Bu}

Sichuan Agricultural University

Jie Ma

Sinohydro Bureau 7 CO.,LTD

Chao Nie

Sinohydro Bureau 7 CO.,LTD

\section{Yang Zhang}

Sichuan Institute of Land Space Ecological Restoration and Geological Disaster Prevention

\section{Research Article}

Keywords: rainfall, increased runoff, UHRRB, SWAT, Budyko Framework 
Posted Date: December 9th, 2020

DOI: https://doi.org/10.21203/rs.3.rs-118409/v1

License: (c) (i) This work is licensed under a Creative Commons Attribution 4.0 International License. Read Full License 


\title{
Increasing Rainfall and Runoff in Alpine Mountainous Areas Can't Completely Eliminate Drought Driven by Temperature Rise
}

\author{
Yu Deng ${ }^{a *}$, Zhifeng Guo ${ }^{a *}$, Fuquan $\mathrm{Ni}^{\mathrm{a}}{ }^{\star}$, Lianqing Xue ${ }^{\mathrm{b} \bowtie}$, Yiping $\mathrm{Wu}^{\mathrm{c}}$, Ouping Deng ${ }^{\mathrm{d}}$, Man \\ Zhou ${ }^{\text {a }}$ Jian $\mathrm{Hu}^{\text {a }}$, Ying Zhang ${ }^{\text {a }}$, Ruihan $\mathrm{Bu}^{\text {a }}$, Jie Ma ${ }^{\mathrm{e}}$, Chao Nie ${ }^{\mathrm{e}}$, Yang Zhang ${ }^{\mathrm{f}}$ \\ ${ }^{a}$ College of Water Conservancy and Hydropower Engineering, Sichuan Agricultural University, Ya'an, 625014, P.R.China. \\ ${ }^{b}$ Hydrology and Water Resources College, Hohai University, Nanjing, 210098, P.R. China. \\ 'Xi'an Jiaotong University, Xi'an, 710051, P.R. China. \\ ${ }^{d}$ College of Resources, Sichuan Agricultural University, Chengdu, 611130, P.R.China.
}

eSinohydro Bureau 7 CO.,LTD, Chengdu 610000, P.R.China.

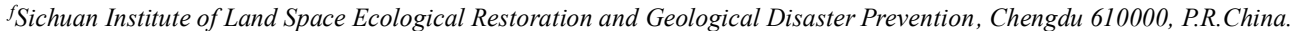

*These authors contributed equally: Yu Deng and Zhifeng Guo. Corresponding author at: College of Water Conservancy and

Hydropower Engineering, Sichuan Agricultural University, Ya'an, 625014, P.R.China;Hydrology and Water Resources College, Hohai University, Nanjing,210098,P.R.China._E-mail address:nfq1965@163.com; lqxue@hhu.edu.cn

\begin{abstract}
Drought research under climate change is of great scientific significance. For Land Use and Land Cover Change (LUCC), temperature and rainfall in climate change, which factor has a greater impact on runoff change in alpine mountainous areas? Can the increase of rainfall in the alpine mountainous area completely eliminate the drought driven by temperature rise? This study takes the upper reaches of Heihe River basin (URHRB) as an example, the URHRB's Soil and Water Assessment Tool (SWAT) model is constructed. Based on 58 scenarios and The Budyko Framework, here we show that a)climate change has a greater contribution to runoff than LUCC, effect of increased rainfall greater than temperature rising on runoff in alpine mountainous area; b)the drought of $57.14 \%$ of UHRRB's sub-basins have eased, $42.86 \%$ of the sub-basins is more serious, the increase in rainfall can't completely eliminate the drought driven by temperature rise. This study coupling SWAT simulation with Budyko Framework and other methods solves the problem of lack of data in alpine mountainous areas, and more accurately quantifies the impact of climate change, LUCC on runoff changes, realizing theoretical and method innovation. The results of this study provide a scientific paradigm for solving scientific problems in similar regions in China and other countries, and have important promotion value.
\end{abstract}


Keywords: rainfall; increased runoff; UHRRB; SWAT; Budyko Framework 


\section{Introduction}

The alpine areas are the sources of many rivers, and they have powerful functions at water conservation and regulation, water ecological environment, and water security ${ }^{1,2}$. There are many river runoff formed at the upper alpine areas in the world. The upstream river channel determines the amount of water resources sent to the middle and lower reaches, thereby restricting the sustainable development of social economy in the middle and lower reaches. Therefore, exploring the characteristics, paths and formation processes of runoff changes in alpine areas has important practical significance for the prevention and control of water pollution, improvement of water environment, protection of water safety, scientific management, and sustainable development of social economy ${ }^{3}$.

The formation process of runoff in alpine regions is more complicated than that in warm regions. Many scientific questions still need to be answered. The most prominent ones are as follows: What is the main reason for the change of runoff in the alpine areas? What mechanism is it regulated? For temperature and rainfall in climate change, which factor has a greater impact on runoff change in alpine mountainous areas? Can the increase of rainfall in the alpine mountainous area completely eliminate the drought driven by temperature rise?

Drought research under climate change is of great scientific significance. In recent years, many domestic and foreign scholars have conducted analysis and research on the attribution analysis of watershed runoff changes ${ }^{4,5,6}$. Commonly used methods include simple empirical curve method (such as rainfall-runoff double accumulation curve, etc.), hydrological model analysis method. Budyko Framework and various empirical formulas derived from it comprehensively consider the interaction between various factors in the watershed ${ }^{7,8,9}$, and the introduction of underlying surface parameters makes the method have a certain physical mechanism ${ }^{10,11,12}$, with the calculation being relatively simple and convenient ${ }^{13,14,15}$. The Budyko hydrothermal coupling equation uses a large number of parameters in parameter calculations ${ }^{16,17,18}$. At present, domestic and foreign researches are very dependent on monitoring data, and are unable to do anything about sub-catchments with missing data; they often replace sub-catchments with the entire watershed; the statistics are too small ${ }^{19}$. How to realize the transformation from the whole basin to sub-basin and grid is very important, and SWAT model considers the comprehensive influence of various important factors. Therefore, carrying out relevant research based on the results of SWAT 
simulation is of great significance to solve the problem of missing data in some watersheds ${ }^{20,21,22}$. The temporal and spatial evolution of surface runoff is to a large extent caused by land use and climate change, and is caused by the interaction of elements in the basin system ${ }^{23,24}$. Using the SWAT model to predict future hydrological responses is conducive to proposing reasonable watershed management measures for different future scenarios. This study coupling SWAT simulation with Budyko Framework and other methods solves the problem of lack of data in alpine mountainous areas, and more accurately quantifies the impact of climate change, LUCC on runoff changes. The major objectives and motivation of this study are to use these methods and models to a) identify the trend and sudden year with temperature, rainfall, potential evaporation $\left(\mathrm{ET}_{0}\right)$, relative moisture index $(\mathrm{M})$, etc.; b) simulate the UHRRB runoff, explore the impact of LUCC and climate (rainfall, temperature) changes on runoff, and find the main influencing factors of runoff changes; c) respond to people's following concerns: Compared with LUCC, which factor has a greater impact on runoff changes in alpine mountainous areas? Compared with rainfall, which factor has a greater impact on runoff changes in alpine mountainous areas? Can the increase in rainfall in the alpine mountainous area completely eliminate the drought driven by temperature rise?

The disposable income of URHRB residents is low. The National Development and Reform Commission had approved the Qilian Mountain Ecological Protection and Comprehensive Management Plan. The main construction content includes wetland ecological protection, water and soil conservation, water resources protection, glacier environmental protection, and scientific and technological support projects. During the "Fourth Five-Year Plan" period, the Qilian Mountain Heihe River Basin Ecological Protection Project will be listed as a provincial major project. Therefore, this study selects UHRRB as the study area. Based on Budyko Framework, SWAT model, etc. to carry out related research, provide theoretical support for the ecological protection of the basin, and provide new ideas for economic growth and ecological development. This has important practical significance and practical value for regional human survival, production, life, ecological environment and the formulation of related policies.

\section{Results}

2.1 Annual runoff and summer, autumn and winter runoff having a better correlation with rainfall; fall and winter runoff having a better correlation with temperature than spring and summer. 
In order to explore the relationship between rainfall, temperature and runoff, the distribution of runoff during the year is divided into four seasons. Spring is from March to May, Summer is from June to August, Autumn is from September to November, and Winter is from December to February of the following year. Fig. 1 is an analysis of the correlation between UHRRB temperature (a), runoff(b) and precipitation at seasonal scales. It can be seen from Fig. 1 that annual runoff and summer, autumn and winter runoff have a better correlation with rainfall; fall and winter runoff have a better correlation with temperature than spring and summer.

2.2 UHRRB temperature rise and precipitation increase simultaneously, indicating that this area is experiencing the transition from a warm and dry climate to a warm and humid climate; at the same time, UHRRB inflows have also shown an increasing trend

The main meteorological factors affecting runoff are temperature, rainfall, $\mathrm{ET}_{0}{ }^{25-27}, \mathrm{M}$ (moist index) is used to explore the interannual drought changes in the study area. Methods such as Mann-Kendall Trend Method (MK) ${ }^{28,29}$ and Cumulative Departure Curve Inspection Method $(\mathrm{CDC})^{30}$ are used to detect and diagnose the average annual temperature, rainfall, runoff, $\mathrm{ET}_{0}$ and M from 1981 to 2014, and the results are shown in Supplementary Fig. 1. The year of sudden change in average annual temperature was 1997, and the year of sudden change in average annual rainfall, runoff, $\mathrm{ET}_{0}$ and $\mathrm{M}$ was 2004; the average annual temperature, rainfall, runoff, $\mathrm{ET}_{0}$ and $\mathrm{M}$ all show an upward trend, of which the average annual temperature has a significant increase. From 1981 to 2014 , and the average temperature rise was $0.0538^{\circ} \mathrm{C} / \mathrm{a}$, which was 8.27 times the global average temperature rise of $0.85^{\circ} \mathrm{C}$ in more than 130 years from 1880 to 2012 . The $\mathrm{ET}_{0}$ increased about $70.89 \mathrm{~mm}$ from 1981 to 2014 , and the rising rate is about $2.09 \mathrm{~mm}$ per year ${ }^{31}$.

\subsection{Climate change has a greater impact on runoff than LUCC}

In order to compare the impact of LUCC and climate changes on runoff, the SWAT model is built to calculate the runoff, based on S1-S4 scenarios such as LUCC and climate changes. The results are shown in Table 1. It can be seen from Table 1 that the runoff of scenarios 1, 2, 3, and 4 are $58.16 \mathrm{~m}^{3} / \mathrm{s}, 52.88 \mathrm{~m}^{3} / \mathrm{s}, 58.94 \mathrm{~m}^{3} / \mathrm{s}, 53.66 \mathrm{~m}^{3} / \mathrm{s}$, respectively.

(1) Taking S4 as the base period, compared with S2, we can get: The climatic conditions remain unchanged from 1981 to 2003, considering the change of single factor of land use relative to 1980 in 2015 , runoff was only reduced by $0.78 \mathrm{~m}^{3} / \mathrm{s}$, and the change rate was $-1.45 \%$. According to the analysis results of the land use transfer matrix ${ }^{32,33}$, the change rates of AGRL, BARR, 
FRST, PAST, URLD and WATR in this area from 2004 to 2014 were $0.00 \%,-7.30 \%, 0.82 \%$, $5.91 \%, 0.00 \%, 0.57 \%$, respectively. $71.58 \%$ of the reduced bare land area is converted into grassland, $23.21 \%$ is converted into forest land, and $5.13 \%$ is converted into water bodies and wetlands. Therefore, from 2004 to 2014, from the perspective of LUCC, the conversion of bare land to grassland and woodland caused a decrease in runoff in the study area.

(2) Taking S4 as the base period, by comparing S3 and S4, we can get: Under the condition of unchanged land use in 1980 and considering the climate change conditions in 2004-2014 compared with 1981-2003, the average annual runoff increased by $5.28 \mathrm{~m}^{3} / \mathrm{s}$ and the rate of change reached $+9.84 \%$. After analysis, the average temperature and average rainfall in the basin during 2004-2014 were both higher than those in 1981-2003. Therefore, during 2004 and 2014, from the perspective of climate change, the increase in temperature and rainfall caused an increase in runoff in the study area.

(3) Taking S4 as the base period, by comparing and analyzing S1 and S4, we can get: Considering the combined effect of LUCC in 2015 compared with LUCC in 1980 and climate change from 2004 to 2014 compared with climate change from 1981 to 2003, the results showed that the average annual runoff increased by $4.50 \mathrm{~m}^{3} / \mathrm{s}$ and the change rate reached $+8.39 \%$.

(4) As the results above, we can find that from 2004 to 2014, the decrease in annual runoff caused by UHRRB's LUCC (-1.45\%) was not only smaller than the increase in annual runoff caused by climate change $(+9.84 \%)$, but also less than the combined effect of LUCC and climate change (+8.39\%). Compared with land use, climate change played a leading role in UHRRB runoff changes.

(5) The contribution rate of climate change and land use LUCC are $85.23 \%$ and $14.77 \%$, respectively, indicating that the impact of climate change on runoff is far greater than that of LUCC. Under the combined effects of climate change and LUCC, runoff is still keep the trend of increasing, which is conducive to the conservation and regulation of water resources in the basin, the improvement of water ecological environment and water security.

2.4 Increasing rainfall has a greater impact on runoff than temperature rising under climate change scenarios 
In order to compare the impact of rainfall and temperature changes on runoff and $\mathrm{ET}_{0}$, the SWAT model is built to calculate the runoff and $\mathrm{ET}_{0}$, based on $\mathrm{S} 1$ and $\mathrm{S} 5$-S58 scenarios such as rainfall and temperature changes(see Supplementary Table 1). On account of the influence of rainfall on $\mathrm{ET}_{0}$ is extremely insignificant, it is ignored in this study. The results are shown in Fig. 2. It can be seen from Fig. 2 that when the temperature decreases, surface runoff increases; when the temperature rises, the changes in surface runoff present uncertainty, due to the conflicting effects caused by evaporation and snowmelt runoff; when precipitation increases and temperature decreases, runoff increases the most; when temperature increases and precipitation decreases, runoff decreases most significantly. The main results were as follows:

It can be seen from Fig. 2 that when the temperature keeps invariant, and the precipitation increases or decreases by $10 \%$ and $20 \%$, the average annual runoff increases by $7.45 \%, 14.69 \%$ and decreases by $20.85 \%$ and $30.61 \%$, respectively. The temperature drops or rises by $0.5^{\circ} \mathrm{C}, 1^{\circ} \mathrm{C}$, $1.5^{\circ} \mathrm{C}, 2^{\circ} \mathrm{C}$ and $3^{\circ} \mathrm{C}$, the average annual runoff increases by $21.61 \%, 17.40 \%, 13.14 \%, 9.10 \%$, $4.35 \%, 9.20 \%, 6.28 \%, 5.36 \%, 4.43 \%$ and $3.95 \%$. The absolute average of the former is 4 times the absolute average of the latter, suggesting that the runoff of alpine mountain rivers is most affected by precipitation. Although temperature has a certain effect on runoff, it is relatively small.

In the horizontal direction, under the air temperature conditions of $-3^{\circ} \mathrm{C},-2^{\circ} \mathrm{C},-1.5^{\circ} \mathrm{C},-1^{\circ} \mathrm{C}$, $-0.5^{\circ} \mathrm{C}, 0^{\circ} \mathrm{C}, 0.5^{\circ} \mathrm{C}, 1^{\circ} \mathrm{C}, 1.5^{\circ} \mathrm{C}, 2^{\circ} \mathrm{C}, 3^{\circ} \mathrm{C}$, the runoff increases with the increase of $-20 \%,-10 \%, 0 \%$, $10 \%$ and $20 \%$ of rainfall, and the maximum multiple of the increase is $1.54-1.88$; Vertically, under $-20 \%,-10 \%, 0 \%, 10 \%$, and $20 \%$ rainfall conditions, increasing runoff has no linear relationship with the increase of temperature $-3^{\circ} \mathrm{C},-2^{\circ} \mathrm{C},-1.5^{\circ} \mathrm{C},-1^{\circ} \mathrm{C},-0.5^{\circ} \mathrm{C}, 0^{\circ} \mathrm{C}, 0.5^{\circ} \mathrm{C}, 1^{\circ} \mathrm{C}, 1.5^{\circ} \mathrm{C}, 2^{\circ} \mathrm{C}$ and $3^{\circ} \mathrm{C}$.

When the temperature decreases and the precipitation decreases (S19-S28), the decrease in temperature will lead to an increase in runoff, and the decrease in precipitation will lead to a decrease in runoff. The response rate of average temperature rise to average runoff is $-3.29 \mathrm{~m}^{3} /\left(\mathrm{s} \cdot{ }^{\circ} \mathrm{C}\right)$, and the percentage response rate of average temperature rise to average runoff is $-4.16 \% / 72.88 \%$, that is, $-1.94 \% / 10 \%$; The response rate of average rainfall to average runoff is $+0.1179 \mathrm{~m}^{3} /(\mathrm{s} \cdot \mathrm{mm})$, and the percentage response rate of average rainfall to average runoff is $+8.34 \% / 10 \%$, indicating that the response rate of average annual rainfall to average annual runoff is much greater than the response rate of average annual temperature rise to average annual runoff. 
On account of the influence of rainfall on $\mathrm{ET}_{0}$ is extremely insignificant, when the temperature decreases and the precipitation consist (S19-S23), the response rate of the average temperature rise to the average $\mathrm{ET}_{0}$ is $19.98 \mathrm{~mm} /{ }^{\circ} \mathrm{C}$. The percentage response rate of the average temperature rise to the average $\mathrm{ET}_{0}$ is $8.77 \% / 72.88 \%$, which is $1.20 \% / 10 \%$. The response rate of the average temperature rise to the average $\mathrm{H}$ is $-0.0245 /{ }^{\circ} \mathrm{C}$, and the percentage response rate of average temperature rise to average drought intensity $(\mathrm{H})$ is $-8.22 \% / 72.88 \%$, that is, $-1.13 \% / 10 \%$. The response rate of average rainfall to average $\mathrm{H}$ is $+0.0002 / \mathrm{mm}$, and the percentage response rate of average rainfall to average runoff is $+0.067 \% / 10 \%$.

When the temperature decreases and the precipitation increases (S29-S38), the decrease in temperature will lead to an increase in runoff, and the increase in precipitation will lead to an increase in runoff. And when the temperature drops by $3{ }^{\circ} \mathrm{C}$ and the rainfall increases by $20 \%$, the runoff has a maximum value; The response rate of the average temperature rise to the average runoff is $-5.15 \mathrm{~m}^{3} /\left(\mathrm{s}^{\circ}{ }^{\circ} \mathrm{C}\right)$, and the percentage response rate of the average temperature rise to the average runoff is $-22.15 \% / 72.88 \%$, which is $-3.44 \% / 10 \%$; The response rate of average rainfall to average runoff is $+0.1780 \mathrm{~m}^{3} /(\mathrm{s} \cdot \mathrm{mm})$, and the percentage response rate of average rainfall to average runoff is $+12.59 \% / 10 \%$, indicating that the response rate of average annual rainfall to average annual runoff is much greater than that of average annual temperature rise to average annual runoff. The response rate of the average temperature rise to the average $\mathrm{ET}_{0}$ is $19.98 \mathrm{~mm} /{ }^{\circ} \mathrm{C}$. The percentage response rate of the average temperature rise to the average $\mathrm{ET}_{0}$ is $8.77 \% / 72.88 \%$, which is $1.20 \% / 10 \%$.The response rate of the average temperature rise to the average $\mathrm{H}$ is $-0.033 /{ }^{\circ} \mathrm{C}$, and the percentage response rate of average temperature rise to average $\mathrm{H}$ is $-11.07 \% / 72.88 \%$, that is, $-1.52 \% / 10 \%$. The response rate of average rainfall to average $\mathrm{H}$ is $+0.0002 / \mathrm{mm}$, and the percentage response rate of average rainfall to average runoff is $+0.067 \% / 10 \%$ 。

When the temperature rises and the precipitation decreases (S39-S48), the increase in temperature will lead to a decrease in runoff, and the decrease in precipitation will lead to a decrease in runoff. And when the temperature rises by $3^{\circ} \mathrm{C}$ and the precipitation decreases by $20 \%$, the runoff is at a minimum. The response rate of average temperature rise to average runoff is $-1.820 \mathrm{~m}^{3} /\left(\mathrm{s} \cdot{ }^{\circ} \mathrm{C}\right)$, and the percentage response rate of average temperature rise to average runoff is $-7.75 \% / 72.88 \%$, that is, $1.06 \% / 10 \%$; The response rate of average rainfall to average runoff is 
$+0.1572 \mathrm{~m}^{3} /(\mathrm{s} \cdot \mathrm{mm})$, and the percentage response rate of average rainfall to average runoff is $+11.12 \% / 10 \%$, indicating that the response rate of average annual rainfall to average annual runoff is much greater than the response rate of average annual temperature rise to average annual runoff. When the temperature decreases and the precipitation consist (S39-S43), the response rate of average temperature rise to average $\mathrm{ET}_{0}$ is $21.96 \mathrm{~mm} /{ }^{\circ} \mathrm{C}$. The percentage response rate of the average temperature rise to the average $\mathrm{ET}_{0}$ is $9.64 \% / 72.88 \%$, which is $1.32 \% / 10 \%$. The response rate of the average temperature rise to the average $\mathrm{H}$ is $-0.021 /{ }^{\circ} \mathrm{C}$, and the percentage response rate of average temperature rise to average $\mathrm{H}$ is $-7.04 \% / 72.88 \%$, that is, $-0.97 \% / 10 \%$. The response rate of average rainfall to average $\mathrm{H}$ is $+0.00017 / \mathrm{mm}$, and the percentage response rate of average rainfall to average runoff is $+0.057 \% / 10 \%$.

When the temperature rises and the rainfall increases (S49-S58), the increase in temperature will lead to an increase in runoff, and an increase in rainfall will lead to an increase in runoff. The reason of increased runoff caused by rising temperatures may be a conflict effect between evaporation and snowmelt. The response rate of average temperature rise to average runoff is $+2.36 \mathrm{~m}^{3} /\left(\mathrm{s} \cdot{ }^{\circ} \mathrm{C}\right)$, and the percentage response rate of average temperature rise to average runoff is $+10.16 \% / 72.88 \%$, that is, $+1.39 \% / 10 \%$. The response rate of average temperature rise to average $\mathrm{ET}_{0}$ is $21.96 \mathrm{~mm} /{ }^{\circ} \mathrm{C}$. The percentage response rate of the average temperature rise to the average $\mathrm{ET}_{0}$ is $9.64 \% / 72.88 \%$, which is $1.32 \% / 10 \%$. The response rate of average rainfall to average runoff is $+0.169 \mathrm{~m}^{3} /(\mathrm{s} \cdot \mathrm{mm})$, and the percentage response rate of average rainfall to average runoff is $+11.99 \% / 10 \%$, indicating that the response rate of average annual rainfall to average annual runoff is much greater than that of average annual temperature rise to average annual runoff. The response rate of the average temperature rise to the average $\mathrm{H}$ is $-0.028 /{ }^{\circ} \mathrm{C}$, and the percentage response rate of average temperature rise to average $\mathrm{H}$ is $-9.39 \% / 72.88 \%$, that is, $1.29 \% / 10 \%$. The response rate of average rainfall to average $\mathrm{H}$ is $+0.00017 / \mathrm{mm}$, and the percentage response rate of average rainfall to average runoff is $+0.057 \% / 10 \%$.

Through the scenario settings of S19-S58, the variation values and rates of runoff, $\mathrm{ET}_{0}$ and $\mathrm{H}$ caused by meteorological factors in this study area are shown in the Supplementary Fig.2. and is mainly related to the change of temperature, which is consistent with the research conclusions of $\mathrm{Yao}^{34}$. $\mathrm{ET}_{0}$ increases with the increase of temperature, for every $1{ }^{\circ} \mathrm{C}$ increase in temperature, $\mathrm{ET}_{0}$ increases by $20.92 \mathrm{~mm}$. 
2.5 Increasing rainfall and runoff can't completely eliminate the drought driven by temperature rise

Under the conditions of Budyko Framework, compared with the 21 sub-basins of UHRRB during 2004-2014 and 1981-2003, the relative change rate and spatial distribution of runoff are shown in Fig. 3(a)-(b). It can be seen from Fig. 3(a)-(b) that the UHRRB runoff has an overall increasing trend. The runoff of the No. 14-21 sub-basin in the Dongcha (Babao River) of the Heihe River in the southeast has slightly decreased, with the highest decrease of $5.40 \%$; The runoff of Xicha (Yeniugou River) and UHRRB main stream of Heihe River in the northwest increases significantly, with the highest increase of $27.62 \%$.

The response results of the 21 sub-basins of URHRB to each influencing factor are shown in Fig. 3(c), and the contribution rate of each influencing factor to the change of runoff in each sub-basin is shown in Fig. 3(d).

It can be seen from Fig. 3(c) that the contribution rate of rainfall to runoff in $100 \%$ of the sub-basins is positive; the contribution rate of $\mathrm{ET}_{0}$ to runoff in $100 \%$ of the sub-basins is negative; The contribution rate of the underlying surface change to runoff in $33.33 \%$ of sub-basins is positive, which is mainly distributed in the sub-basins of No. 4, 6, 7, 8 and 11-13 in the middle of URHRB.The main reason may be the conversion of woodland in the middle of the basin to grassland. The contribution rate of the underlying surface change to runoff in $66.67 \%$ of sub-basins is negative. The main reason may be the conversion of bare land in the northwest and southeast into forest and grassland.

It can be seen from Fig. 3(d) that $100 \%$ of the sub-basin rainfall contributes more than $50 \%$ to runoff. And $57.14 \%$ of the sub-basin rainfall makes a dominant contribution to runoff, which is mainly distributed in the 1-10 and $12-13$ sub-basins; $42.86 \%$ of the sub-basin $\mathrm{ET}_{0}$ makes a dominant contribution to runoff, mainly distributed in the $11,14-21$ sub-basins; $100 \%$ of the underlying surface changes in the sub-watershed are not the dominant factor. This conclusion is close to the land use contribution rate calculated based on the simulation results of SWAT model, which is only $14.77 \%$. Among the 13 sub-basins where runoff is increasing, $92.13 \%$ of the sub-basins have rainfall as the dominant factor, which further proves that rainfall is the main reason for the increase in runoff in alpine mountainous areas. At the same time, it also shows that 
the increase in rainfall cannot completely eliminate the drought driven by temperature rise in the alpine mountainous area.

To further explore the relationship between rainfall and drought, the 21 sub-basins of UHRRB were compared with $\mathrm{H}$ during 2004-2014 and 1981-2003. The results are shown in Fig. 4(a)-(b). It can be seen from the figure that the drought degree of the No. 13 sub-watershed has changed from Slight to No drought; the drought degree of the No. 16 sub-basin changed from Moderate to Severe, and there was no change in the division of drought in the remaining sub-basins; the $\mathrm{H}$ values of No. 1-10 sub-basin and No. 12-13 sub-basin all increased; the $\mathrm{H}$ values of No. 11 sub-basin and No. 14-21 sub-basin all decreased. Comparing Fig. 3(d) and Fig. 4(c), H change in the study area is basically the same as the runoff change. Compared with the period of 1981-2003 between 2004 and 2014, the 11th sub-basin was drier, but the reason for the increase in runoff may be that the 11th sub-basin was more arid than the base period. However, it is caused by the increased runoff concentration in the upstream 1-10 and 12-13 sub-basins.

Compared with 1981-2003, the change of $\mathrm{H}$ in each sub-basin from 2004 to 2014 and the change of $\mathrm{H}$ in each sub-basin are shown in Fig. 4(c), respectively. It can be seen from the figure that $57.14 \%$ of UHRRB's sub-basins have increased $\mathrm{H}$ values, that is, drought has eased. Drought relief was the most obvious in the No. 13 sub-watershed, with an increase in $\mathrm{H}$ value of 0.051 . D relief in the No. 2 sub-watershed was the least obvious, with an increase in $\mathrm{H}$ of 0.003 ; The $\mathrm{H}$ of $42.86 \%$ of the sub-watersheds has all decreased, that is, the drought is more serious. Drought was the most severe in the No. 18 sub-watershed, with a decrease in $\mathrm{H}$ value of 0.04 ; in the No. 16 sub-watershed, the decrease was the least significant, with a decrease in $\mathrm{H}$ value of 0.022 .

In summary, from the perspective of each sub-basin, in the case of the overall increase in rainfall in the study area, there are still some sub-basins with more severe droughts, indicating that the increase in rainfall cannot completely eliminate the drought driven by temperature rise in the alpine mountainous area.

This finding is well confirmed in the research conclusions of Ma ${ }^{35}$ based on the Jinsha River Basin and Yao ${ }^{36}$ based on the runoff of the alpine basin in the Tianshan Mountains.

Global climate change, land use patterns, and human activities make the hydrological process in alpine regions very complex ${ }^{37-39}$. Factors such as air temperature, rainfall, evapotranspiration, runoff, glacier, snowfall, frozen soil, vegetation, groundwater ${ }^{40}$, land use patterns, and human 
activities interact with each other and cause each other, and the relationship is very complex ${ }^{41,42}$. Clarifying the relationship between them is currently a hot topic and scientific issue in domestic and foreign research. At present, domestic and foreign scholars have carried out a lot of research on the situation in different regions, but due to the large uncertainty of climate change, the lack of monitoring data in alpine mountainous areas, and the differences in research data and methods, there are still big differences in relevant research results.

\section{Discussion}

In previous studies, changes in runoff $\left(\mathrm{m}^{3} / \mathrm{s}\right)\left(\right.$ dimension is $\mathrm{m}^{3} / \mathrm{s} /{ }^{\circ} \mathrm{C}$ and $\left.\mathrm{m}^{3} / \mathrm{s} / \mathrm{mm}\right)$ are often compared when rainfall and temperature change is $1{ }^{\circ} \mathrm{C}$ and $1 \mathrm{~mm}$ respectively, and relevant conclusions are drawn. The main problem of this comparison method is the inconsistency of dimensions. This study believes that when the temperature decreases and the rainfall decreases, the percentage response rate of the average temperature rise to the average runoff is $-1.94 \% / 10 \%$, and the percentage response rate of the average rainfall to the average runoff is $+8.34 \% / 10 \%$; When the temperature decreases and the rainfall increases, the response rate of the average temperature rise to the percentage change of the average runoff is $-3.44 \% / 10 \%$, and the response rate of the average rainfall to the percentage change of the average runoff is $+12.59 \% / 10 \%$; When the temperature rises and the rainfall decreases, the response rate of the average temperature rise to the percentage change of the average runoff is $-1.06 \% / 10 \%$, and the response rate of the average rainfall to the percentage change of the average runoff is $+11.12 \% / 10 \%$; When the temperature rises and rainfall increases, the response rate of the average temperature rise to the percentage change of the average runoff is $+1.39 \% / 10 \%$; the response rate of the average rainfall to the percentage change of the average runoff is $+11.99 \% / 10 \%$. It shows that the response of rainfall to runoff is much greater than the response to temperature; the response rate of the average temperature rise to the percentage change of the average $\mathrm{ET}_{0}$ is $+1.32 \% / 10 \%$. Obviously, this study compares the percentage of change in runoff with the percentage of change in rainfall and temperature rise under each scenario, and the dimensions are unified, making the results comparable. Therefore, this method overcomes the main problems and shortcomings in previous studies, and the conclusion is more reliable.

In previous studies, relevant data based on hydrological sites were often used as the basis for the study of the research area. There was no detailed study on the sub-basins of the research area 
above hydrological sites, which could not fully reflect the heterogeneity of the research area, and the research conclusions often cover up many facts. This study couples SWAT simulation with Budyko Framework and other methods, and conducts the research from the scale of the sub-basin, solving the problem of missing data in alpine mountainous areas. It more accurately quantified the impact of climate change and human activities on runoff changes, and came to the important conclusion that the increase in rainfall can't completely eliminate the drought driven by temperature rise. It is more scientific and more realistic, which is conducive to the scientific planning of the green hills, clear water, cultivated land, woodland, grassland and the upper and lower reaches and the left and right banks of the Heihe River Basin.

It should be pointed out that although the research results under different scenarios in this study have the same trend, due to the monitoring errors of hydrology, meteorology, soil, land use and other data, as well as the limitations of the SWAT model and its calibration, and the representativeness of the verification parameters, the calculation results inevitably have certain errors, indicating that the results have a certain degree of uncertainty, which is precisely the inexhaustible motivation and source of our in-depth and continuous research.

\section{Methods}

The Heihe River is the second largest inland river in Northwest China. It originates from the Qilian Mountains, flows through the Hexi Corridor, and ends at Ejinaqi in northern Inner Mongolia; With Yingluoxia Hydrological Station and Zhengyixia Hydrological Station as the boundary, it is divided into upper, middle and lower reaches.

URHRB includes most of Qilian County in Qinghai Province and part of Sunan County in Gansu Province, covering an area of $9,920 \mathrm{~km}^{2}$ (Supplementary Fig. 3). The main rivers include Xicha Yeniugou, Dongcha Babao River, the main stream of the central Heihe Rive. Dongcha is about $75 \mathrm{~km}$ and is between $97^{\circ} 28^{\prime}-101^{\circ} 16^{\prime} \mathrm{E}$ and $37^{\circ} 30^{\prime}-39^{\circ} 41^{\prime} \mathrm{N}$. It is the main runoff producing area of the Heihe River Basin, which is composed of surface runoff, glacier snowmelt water and groundwater ${ }^{43}$. The annual runoff at the outlet of Yingluoxia is 1.58 billion $\mathrm{m}^{3}$. Due to the heavy rainfall and the supply of snowmelt water from glaciers, the underlying surface is a rocky mountainous area with good vegetation. It is a runoff-forming area in the Heihe River Basin. The runoff above the mountain mouth accounts for $88.0 \%$ of the river's natural water volume. The snowline height in the study area gradually rises from east to west, and the glacier coverage rate is 
only $0.5 \%$. The annual average glacier meltwater accounts for only $3.5 \%$ of the runoff (the proportion in dry years is close to $5 \%$, and the proportion in dry months is as high as $16 \%$ ). The remaining $96.5 \%$ of the runoff is made up by rainfall. Glacier retreat has little effect on runoff ${ }^{44}$, but glaciers have an important role in stabilizing runoff and regulating abundance and dryness.

\subsection{Data and sources}

See Supplementary Table. 2.

\subsection{Calculate $M$ and $H$}

$\mathrm{M}$ is suitable for drought monitoring and assessment, the calculation formula is shown in formula (1), and the classification of M is shown in Supplementary Table 3.

$$
\mathrm{M}=\frac{\mathrm{P}-\mathrm{ET}_{0}}{\mathrm{ET}_{0}}
$$

Where, $\mathrm{P}$ is precipitation and $\mathrm{ET}_{0}$ is potential evapotranspiration.

$\mathrm{H}$ is used to evaluate the severity of drought, which is reflected by the average relative humidity index. The calculation formula is shown in formula (2).

$$
\mathrm{H}=\frac{1}{\mathrm{n}} \sum_{i=1}^{\mathrm{n}} \mathrm{M}_{\mathrm{i}}
$$

Where, $\mathrm{n}$ is the number of years of drought, and $\mathrm{M}_{\mathrm{i}}$ is the relative humidity index value when drought occurs.

\subsection{Identification of trends and mutation points}

First, diagnose the correlation between runoff, temperature, rainfall, $\mathrm{ET}_{0}$ and $\mathrm{M}$ on the annual scale and the spring, summer, autumn, and winter scales to assess the correlation between hydrological elements in the inter-annual and intra-annual seasons; Secondly, conduct trend and mutation point analysis and evaluation of runoff, temperature, rainfall, $\mathrm{ET}_{0}$ and $\mathrm{M}$ to determine the base period and change period of the age change. There are many ways to analyze trends and mutation points ${ }^{45}$. This study uses the hydrological time series trend and mutation analysis system developed by Wang ${ }^{46}$ to comprehensively analyze the trend and change point characteristics of the runoff series. The trend test method adopts the linear trend correlation analysis method; the mutation point test adopts the MK and CDC methods.

\subsection{SWAT simulation analysis}

Using the SUFI-2 algorithm in SWAT-CUP software ${ }^{47}$, the SWAT model is calibrated and verified based on the daily meteorological data of 8 weather stations and the measured monthly 
runoff data of 3 hydrological stations in the study area and surrounding areas. Set 1979-1981 as the model warm-up period, 2001-2011 as the model calibration period, and 2012-2014 as the model verification period. The runoff data is repeatedly calibrated. $\mathrm{R}^{2}$, NSE, and PBIAS (see Supplementary Table 4 and Supplementary Fig. 4) are used to evaluate the fit and applicability of the simulated and measured values until they meet requirements, and then perform parameter verification and return. The calculation formulas are as follows:

$$
\begin{gathered}
R^{2}=\frac{\left[\sum_{i}^{n}\left(Q_{m, i}-\overline{Q_{m}}\right)\left(Q_{s, i}-\overline{Q_{s}}\right)\right]^{2}}{\sum_{i}^{n}\left(Q_{m, i}-\overline{Q_{m}}\right)^{2} \sum_{i}^{n}\left(Q_{s, i}-\overline{Q_{s}}\right)^{2}} \\
N S E=1-\frac{\sum_{i}^{n}\left(Q_{m, i}-Q_{s, i}\right)^{2}}{\sum_{i}^{n}\left(Q_{m, i}-\overline{Q_{m}}\right)^{2}} \\
\text { PBIAS }=\frac{\sum_{i}^{n}\left(Q_{s, i}-Q_{m, i}\right)^{2}}{\sum_{i}^{n} Q_{s, i}}
\end{gathered}
$$

Where: $Q_{m}$ is the simulated runoff; $Q_{s}$ is the observed runoff.

4.5 Runoff simulation scenario setting and contribution rate calculation under different land use and climate change based on SWAT model

After diagnosing the applicability of the SWAT model in UHRRB, set and compare the values of 4 (see Supplementary Table 5) to evaluate the single and integrated response of runoff to LUCC and climate change. And quantify the contribution rate of land use and climate change according to formula (6)-formula (10):

Total runoff change:$$
\triangle \mathrm{Q}=\mathrm{Q}_{1}-\mathrm{Q}_{4}
$$

Change in runoff caused by climate change: $\quad \Delta \mathrm{Q}_{\mathrm{C}}=\mathrm{Q}_{1}-\mathrm{Q}_{2}$

Runoff change caused by LUCC: $\quad \triangle \mathrm{Q}_{\mathrm{H}}=\mathrm{Q}_{1}-\mathrm{Q}_{3}$

Contribution rate of climate change: $\quad \eta_{C}=\frac{\left|\Delta Q_{C}\right|}{|\Delta Q|} \times 100 \%$

$$
\text { Contribution rate of LUCC: } \quad \eta_{H}=\frac{\left|\Delta Q_{H}\right|}{|\triangle Q|} \times 100 \%
$$

Where: $\mathrm{Q}_{i}$ represents the runoff simulated by scenario $\mathrm{i}$.

\subsection{Attribution analysis of runoff changes}

Only by accurately quantifying the impact of precipitation, $\mathrm{ET}_{0}$, underlying surface and other factors on runoff can we plan and use water resources more effectively ${ }^{48}$.

This study uses Budyko Framework for attribution analysis. The main formula of Budyko analysis is shown in formula (15)- (19): 


$$
\begin{gathered}
E=\frac{P E_{0}}{\left(P^{n}+E_{0}^{n}\right)^{\frac{1}{n}}} \\
\varepsilon=\frac{\partial R}{\partial X} \frac{R}{X} \\
\triangle R=\left(\varepsilon_{p} \frac{\Delta P}{P}+\varepsilon_{E T_{0}} \frac{\Delta E T_{0}}{E T_{0}}+\varepsilon_{p} \frac{\Delta n}{n}\right) R \\
\eta=\frac{R_{2}-R_{1}}{R_{1}} \times 100 \% \\
\triangle R_{x}=\varepsilon_{x} \frac{R}{x} \triangle x
\end{gathered}
$$

Where: $\mathrm{E}$ is the actual evapotranspiration $(\mathrm{mm}), \mathrm{P}$ is the precipitation $(\mathrm{mm}), \mathrm{E}_{0}$ is the amount of $\mathrm{ET}_{0}(\mathrm{~mm}), \mathrm{n}$ is the underlying surface parameter ${ }^{[49]}, \varepsilon$ is the elastic coefficient, $\mathrm{R}$ is the runoff (mm), and $\Delta \mathrm{R}$ is the runoff change, $\varepsilon_{\mathrm{p}}, \varepsilon_{\mathrm{E} 0}$, and $\varepsilon_{\mathrm{n}}$ represent the precipitation elasticity coefficient, $\mathrm{ET}_{0}$ elasticity coefficient and the underlying surface elasticity coefficient respectively, $\eta$ is the relative change rate of runoff, $R_{1}$ and $R_{2}$ represent the average annual runoff in the base period and the influence period, respectively, and $\Delta R_{x}$ is the influence of the corresponding factor on the change of runoff; $\varepsilon_{\mathrm{x}}$ is the elastic coefficient of each factor to the change of runoff; $\mathrm{x}$ is a certain influencing factor of runoff change, including $\mathrm{P}, \mathrm{E}_{0}$ and $\mathrm{n} ; \Delta \mathrm{x}$ is the amount of change of a certain impact factor in the influence period compared with that in the base period.

\section{References}

1. Lehner, F., Wood, A.W., Vano, J.A. et al. The potential to reduce uncertainty in regional runoff projections from climate models. Nat. Clim. Chang. 9, 926-933 (2019).

2. Li Qiuju,Li Zhanling,Wang Jie.Analysis of runoff changes and their attributions in the upper reaches of the Heihe River Basin. South-to-North Water Diversion and Water Science and Technology 17(03),31-39(2019).

3.Xue, L.Q. et al. Identification of potential impacts of climate change and anthropogenic activities on streamflow alterations in the tarim river basin, china. Sci. Rep. 7(1), 8254 (2017).

4. Jian Hu, Jie Ma, Chao Nie, Lianqing Xue, Yang Zhang, Fuquan Ni, Yu Deng. Attribution Analysis of Runoff Change in Min-Tuo River Basin based on SWAT model simulations, China. Sci. Rep. 10. 1(2020).

5. Dou Xiaodong,Huang Wei,Yi Qi,Liu Xiaozhou,Li Meng,Li Zhongliang.The impact of LUCC and climate change on runoff in the Longchuan River Basin.Acta Eco-Environmental Sciences 
28(01),7-15(2019)

6. Yang Liyan. Simulation study on the impact of climate and land use changes on runoff in Yuanjiang Basin. Yunnan University (2018).

7. Fu Baopu.On the calculation of land surface evaporation.Chinese Journal of Atmospheric Sciences 5(1), 23-31 (1981)

8. Zhang L.,Dawes W. R.,Walker G. R..Response of mean annual evapotranspiration to vegetation changes at catchment scale. Water Resour. Res. 37(3),701-708(2001).

9. Sun Fubao. Research on watershed evapotranspiration based on Budyko water-heat coupling balance hypothesis. Beijing: Tsinghua University (2007).

10. Bian Yumin, Lu Haishen, Tan Juanjuan, et al. Research on basin water balance based on Budyko hypothesis. Yangtze River 45(3),24-28 (2014).

11. Guo Shenglian, Guo Jiali, Hou Yukun, et al. Forecasting future runoff changes in the Yangtze River Basin based on Budyko hypothesis. Prog. in Water Sci. 26(2), 151-160 (2015).

12. Zhao F, Wu Y, Wang L, Liu S, Wei X, Xiao J, et al. Multi-environmental impacts of biofuel production in the U.S. Corn Belt: A coupled hydro-biogeochemical modeling approach. J. Clean. Prod. 251, 119561 (2020).

13. Liu Yanli, Wang Guoqing, Jin Junliang, et al. Definition of the impact of environmental changes on watershed runoff based on Budyko hypothesis. J.Water Res. Water Transp. Eng. $6,1-8(2014)$

14. Wang Weiguang, Lu Wenjun, Xing Wanqiu, et al. Study on the evolution law and attribution of Budyko equation parameter $\mathrm{n}$ in the Yellow River Basin. Water Res. Protect. 34(2), 7-13(2018).

15. Zhang Lianpeng, Liu Dengfeng, Zhang Hongxue, et al. Impacts of climate change and human activities on Beiluo River runoff. Journal of Hydroelectric Engineering 35(7),55-66(2016).

16. Hu Shanshan,Liu Changming,Zheng Hongxing,Wang Zhonggen,Yu Jingjie.The impact of climate change and human activities on the runoff in the water source area of Baiyangdian.Journal of Geographical Sciences 22(05),895-905(2012).

17. Qiang L.,Yanh Z. F.,Cuib S.,et al. Temporal trends of hydro-climatic variables and runoff response to climatic variability and vegetation changes in the Yiluo River Basin,China. Hydrological Processes 23(21),3030-3039(2010). 
18. He Yanzi, Yue Dapeng, Da Xing, et al. A preliminary study on the impact of climate change and human activities on water resources-Taking Shaanxi Province as an example. Jiangxi Journal of Agriculture 28(12),87-93 (2016).

19. Mou Xia, Liu Qiang, Ping Fan, et al. Runoff regime change and its attribution analysis in the Wuding River Basin from 1960 to 2007. Journal of Beijing Normal University (Natural Science Edition) 53(4), 465-471 (2017).

20. Rahman K.,da Silva A. G.,Tejeda E. M.,Gobiet A.,Beniston M.,Lehmann A. An independent and combined effect analysis of land use and climate change in the upper Rhone River watershed,Switzerland. Applied Geography 63, 264-272 (2015).

21. Zhang L,Karthikeyan R,Bai Z K,Srinivasan R. Analysis of streamflow responses to climate variability and land use change in the Loess Plateau region of China. CATENA 154, 1-11 (2017).

22. Feng Chang, Mao Dehua, Zhou Hui, Cao Yanmin, Hu Guangwei. The impact of climate and land use changes on runoff in the Lianshui Basin. Glaciology and Geocryology 39(2): 395-406 (2017).

23. Neitsch S. L., Arnold J. G., Kiniry J. R., Williams J. R. SWAT 2009 Theoretical Foundation. Long Aihua, Zou Songbing, Xu Baorong, Lu Zhixiang, Yin Zhenliang, Wang Dangxian, Translated. Zhengzhou: Yellow River Water Conservancy Press 68-152 (2012).

24. Yuan Yuzhi, Zhang Zhengdong, Meng Jinhua. The impact of land use and climate change on runoff in the Liuxi River Basin based on SWAT model. Chinese Journal of Applied Ecology 26(4), 989-998 (2015).

25. Wu Y, Liu S, Abdul-Aziz OI. Hydrological effects of the increased $\mathrm{CO}_{2}$ and climate change in the Upper Mississippi River Basin using a modified SWAT. Climatic Change 110 (3-4), 977$1003(2012)$.

26. Zhao Anzhou, Zhao Yuling, Liu Xianfeng, Zhu Xiufang, Pan Yaozhong, Chen Shuchen. Research on the impact of climate change and human activities on the blue and green waters of the Weihe River Basin. Geographical Science 36(4), 571-579 (2016).

27. Li Shuai, Wei Hong, Liu Yuan, Ma Wenchao, Gu Yanwen, Peng Yue, Li Changxiao. Runoff simulation of Qingshui River Basin in Ningxia under climate and land use changes. Acta Ecologica Sinica 37(4), 1252-1260 (2017). 
28. Zhao F., Wu Y., Yao Y., Sun K., Zhang X., Winowiecki L., et al. Predicting the climate change impacts on water-carbon coupling cycles for a loess hilly-gully watershed. Journal of Hydrology 124388, 581 (2020).

29. Wu Y., Liu S., Yan W., Xia J., Xiang W., Wang K., et al. Climate change and consequences on the water cycle in the humid Xiangjiang River Basin, China. Stochastic Environmental Research and Risk Assessment 30 (1), 225-235 (2016).

30. Jiang Yao,Xu Zongxue, Wang Jing.Performance comparison of five trend detection methods based on annual runoff series. Journal of Hydraulic Engineering 1-13 (2020).

31. Zhang Wei, Lu Changhe. Assessing Changes in Rainstorms in Beijing During the Last 50 Years, 7(5):372-377 (2016).

32. Li Wei, Li Xiaoxiao, Xu Hongmei. Climate Change and Water Resources Security. (2020).

33. Yue Duan,Xiaochen Wang,Yongjie Wei. Land use change analysis of Daishan Island using multi-temporal remote sensing imagery. Arabian Journal of Geosciences 13-15 (2020).

34. Yao Tianci,Lu Hongwei,Yu Qing,Feng Wei.Characteristics of potential evapotranspiration and its mutation test in the Qinghai-Tibet Plateau and its surrounding areas in the past 50 years.Advance in Earth Science 35(05), 534-546 (2020).

35. Ma Yue. Research on the response of hydrological process of Jinsha River basin to climate change based on SWAT model. Huazhong University of Science and Technology(2018).

36. Yao Junqiang,Yang Qing,Han Xueyun,Liu Yang.The impact of climate change on the changes of water resources in the alpine basin of the Tianshan Mountains: A case study of the Bayinbulak Basin.Arid Zone Research 33(06), 1167-1173 (2016).

37. Qin, Y., Abatzoglou, J.T., Siebert, S. et al. Agricultural risks from changing snowmelt. Nat. Clim. Chang. 10, 459-465 (2020).

38. Rosa, L., Chiarelli, D., Rulli, M., Dell'Angelo, J., \& D'Odorico, P. Global agricultural economic water scarcity. Science Advances 6(18) (2017).

39. Yang Dawen, Zheng Yuanrun, Gao Bing, Li Hongyi, Yu Pengtao. Eco-hydrological process and coupled simulation in alpine mountain area. Beijing: Science Press (2020).

40. Du Yunhao. Research on Optimization of Irrigation Area Deficit Irrigation System Based on Groundwater Depth Prediction. Yangzhou University (2019). 
41. Nie Chao, Ni Fuquan, Deng Yu, Ma Jie, Zhang Yang. The response of the runoff of the Mintuo River Basin to climate and land use changes.Journal of Water Resources and Water Engineering 31(3), 110-118 (2020).

42. Zhang Yang, Deng Yu, Ni Fuquan, Nie Chao, Ma Jie. Analysis of the spatiotemporal characteristics of blue/green water resources in the Mintuo River Basin based on SWAT model. Chinese Journal of Agricultural Meteorology 41(6), 345-356 (2020).

43. Zhen Yulong. Analysis and discussion of runoff evolution in Heihe. Gansu Science and Technology 33(10), 49-50 (2017).

44. Yang Yong,Chen Rensheng,Ji Xibin.Glacier changes in the Yeniugou watershed of Heihe River in recent decades.Journal of Glaciology and Geocryology 1,100-106(2007).

45. Zhou Yuanyuan, Shi Changxing, Fan Xiaoli, et al. Analysis methods of variation points of domestic hydrological sequence and its application in various watersheds.Progress in Geographical Sciences 30(11), 1361-1369 (2011).

46. Wang Yusen. Development and application of trend and catastrophe analysis system for hydrological time series. Gansu Science and Technology 32(9), 36-37,11 (2016).

47. Rahman K.,da Silva A. G.,Tejeda E. M.,Gobiet A., Beniston M., Lehmann A. An independent and combined effect analysis of land use and climate change in the upper Rhone River watershed,Switzerland. Applied Geography 63, 264-272 (2015).

48. Sun P., Wu Y., Wei X., Sivakumar B., Qiu L., Chen J., et al. Quantifying the contributions of climate variation, land use change, and engineering measures for dramatic reduction in streamflow and sediment in a typical Loess watershed, China. Ecological Engineering 142, $105611(2020)$.

49. Xing W., Wang W., Zou S., et al. Projection of future runoff change using climate elasticity method derived from Budyko framework in major basins across China. Global and Planetary Change 162, 120-135 (2018).

\section{Acknowledgements}

This work was supported by Sichuan Science and Technology Program (No. 2018RZ0125) and Rural Water Security Engineering Central Research Program of Sichuan Provincial Department of Education (No. 035Z2289). 


\section{Author contributions}

Yu Deng, Zhifeng Guo, Fuquan Ni, Lianqing Xue and Yiping Wu conseived and desingned the research themes; Zhifeng Guo and Ruihan Bu built the SWAT model; Fuquan Ni, Lianqing Xue and Yiping Wu analyzed the data; Chao Nie, Jie Ma and Yang Zhang contributed to gather the materials; Zhifeng Guo and Yu Deng wrote the study; Fuquan Ni, Lianqing Xue and Yiping Wu revised the study. All authors have contributed to the revision and approved the manuscript.

\section{Competing interests}

The authors declare no competing interests.

\section{Figures}
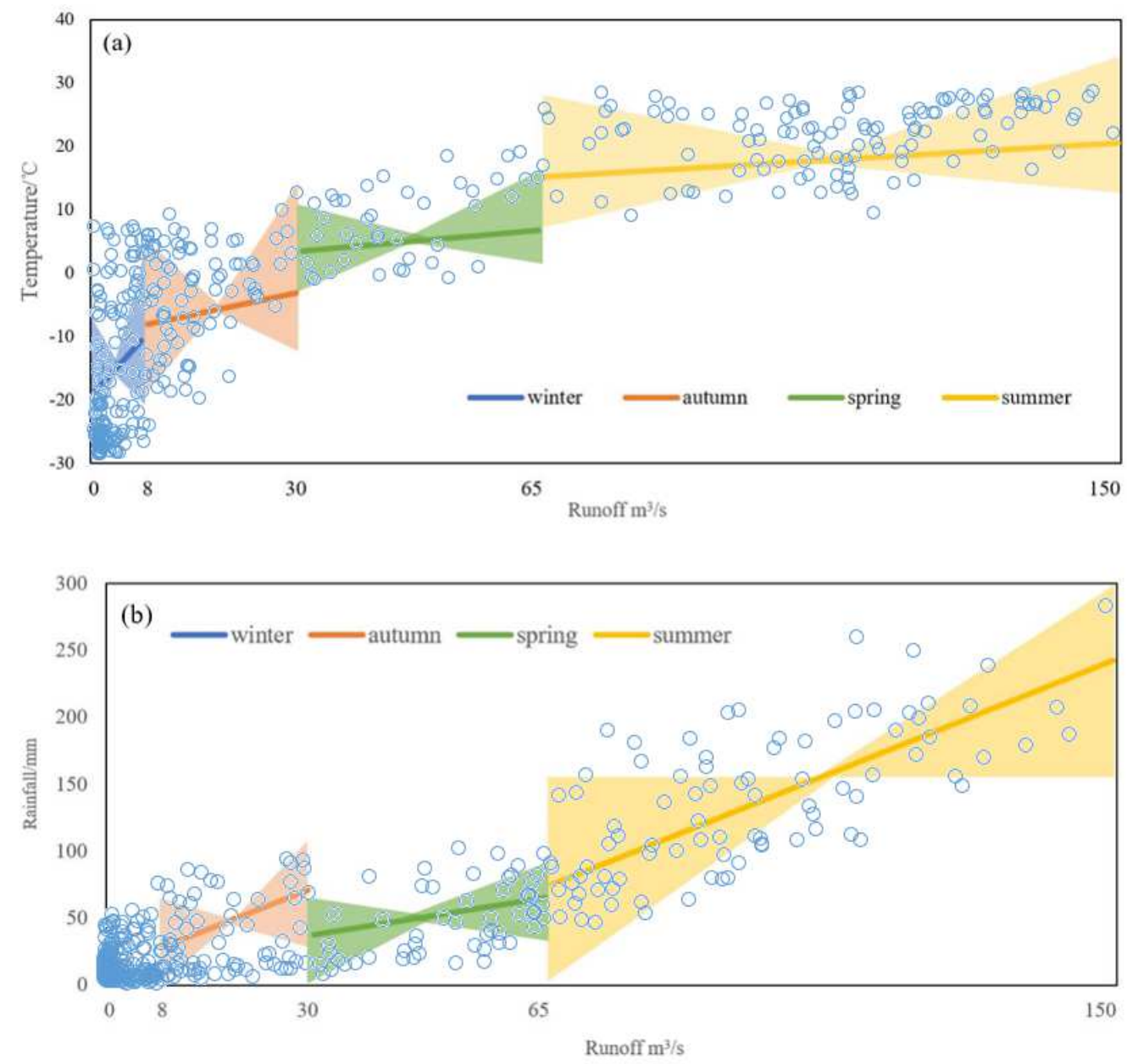

Fig. 1 Correlation analysis of temperature(a),runoff(b) and rainfall. The slope of the four lines in Fig.1(a) represents the influence degree of temperature on runoff. The higher the slope is, the greater the 
influence degree of rainfall on runoff in that season is. The shadowed part in Fig.1(a) shows the distribution of temperature in that season. The slope of the four lines in Fig.1(b) represents the influence degree of rainfall on runoff. The higher the slope is, the greater the influence degree of rainfall on runoff in that season is. The shadowed part in Fig1. (b) shows the distribution of rainfall in that season. It should be noted that because the units of temperature and rainfall are different, the slopes between a and $\mathrm{b}$ cannot be compared.

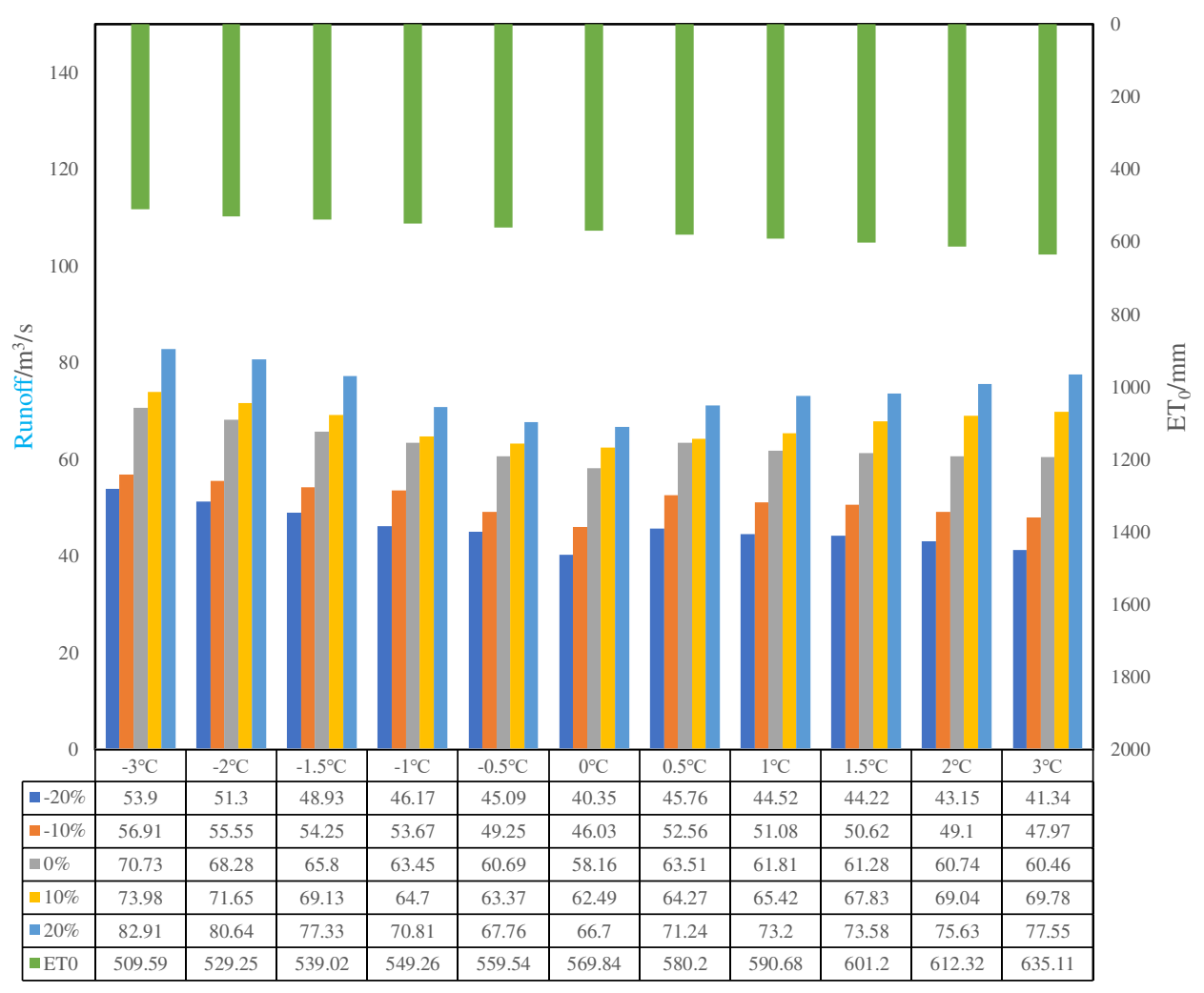

Fig. 2 Runoff simulation results under combined change scenarios of temperature and rainfall 

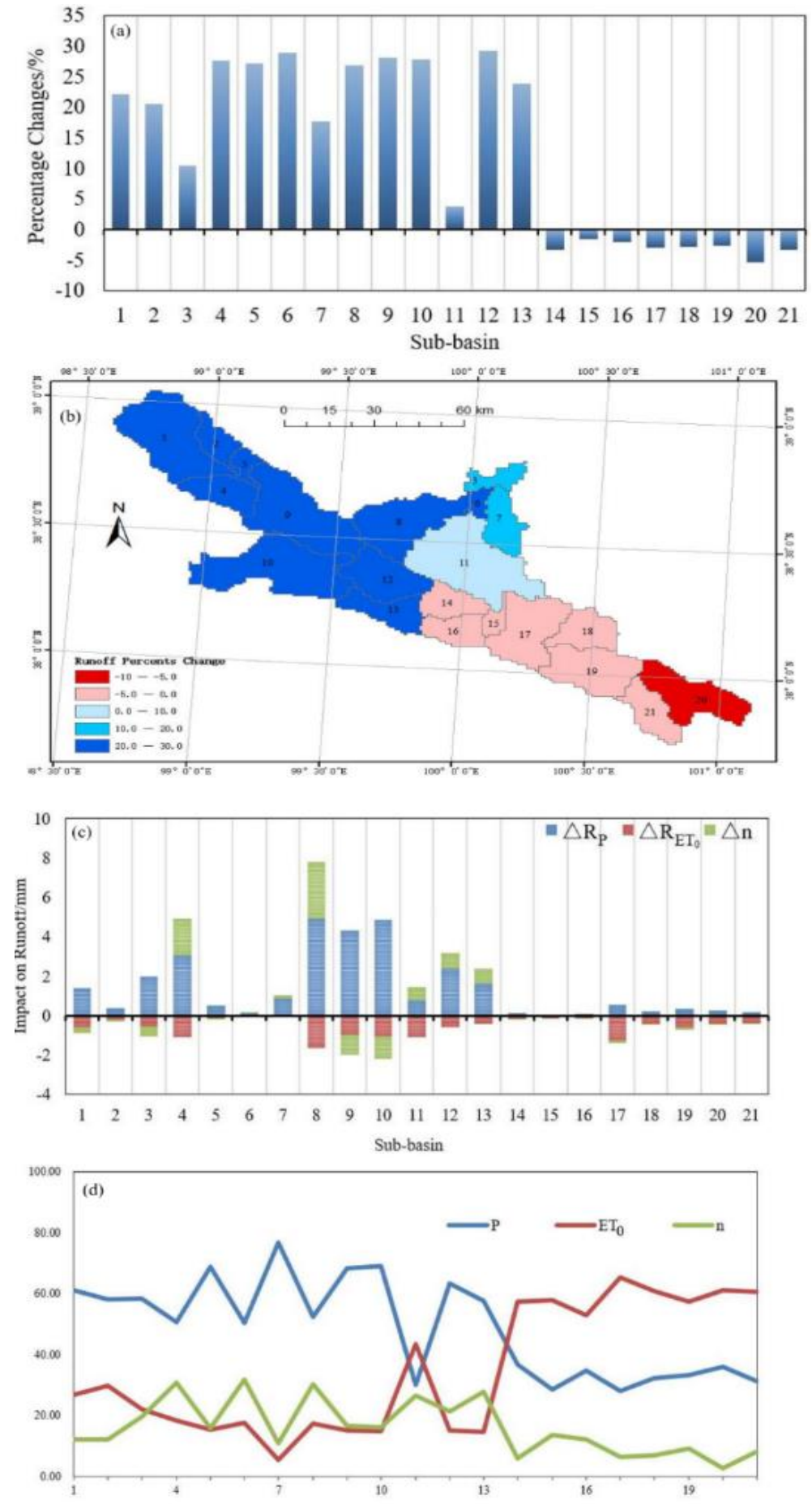

Fig. 3 Runoff change and contribution rate of each factor in each sub-basin. Relative change rate of runoff in each sub-basin (a), spatial distribution of relative change rate of runoff (b), the response of each sub-basin to each factor (c), the contribution rate of each factor to the runoff change of each sub-basin (d). 

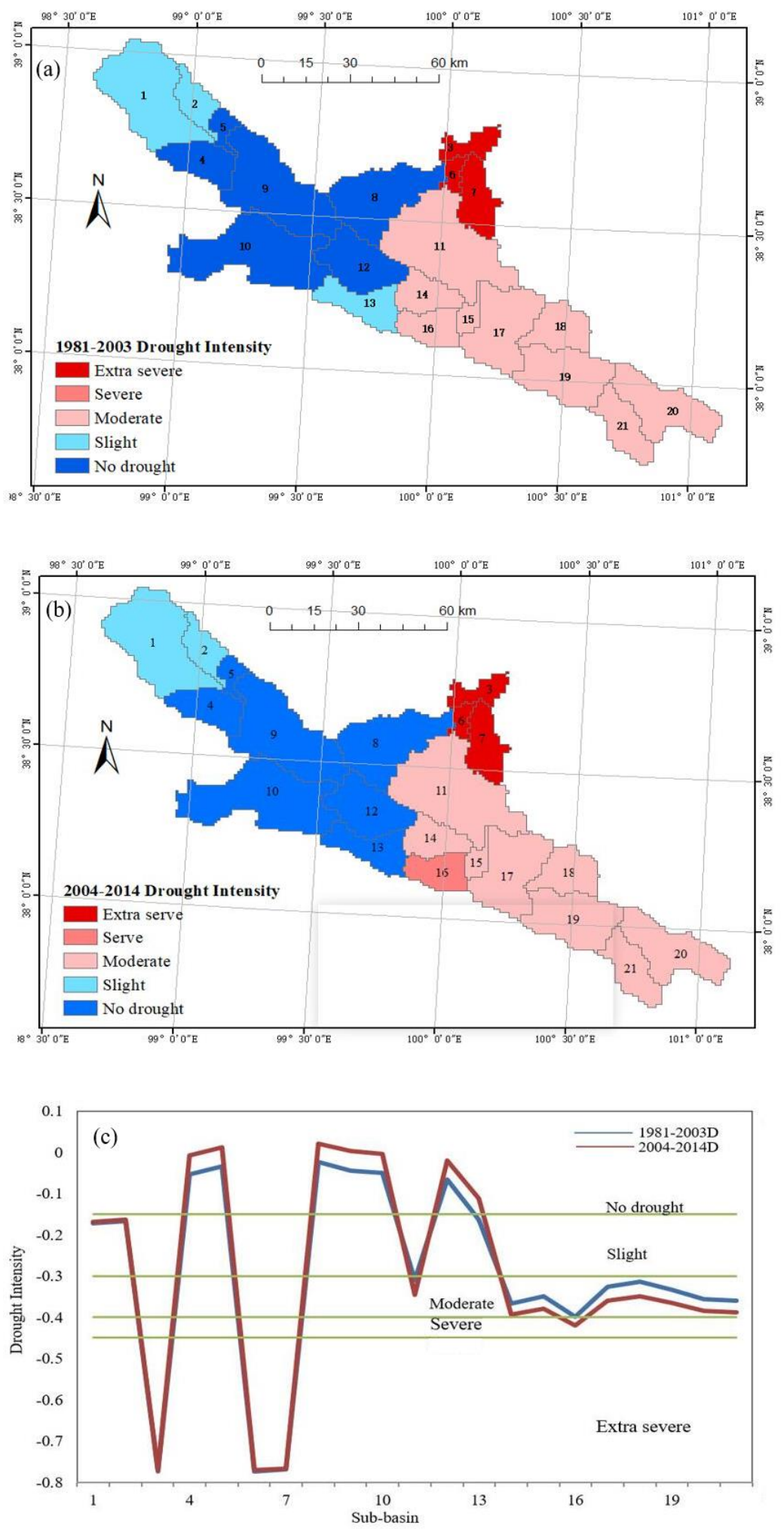

Fig. 4 Spatiotemporal variation characteristics of $\mathrm{H}$ values. $\mathrm{H}$ values in each sub-basin from 1981 to 2003 (a), $\mathrm{H}$ values in each sub-basin from 2004 to 2014 (b), changes in $\mathrm{H}$ value in each sub-basin between 2004-2014 and 1981-2003 (c). 


\section{Tables}

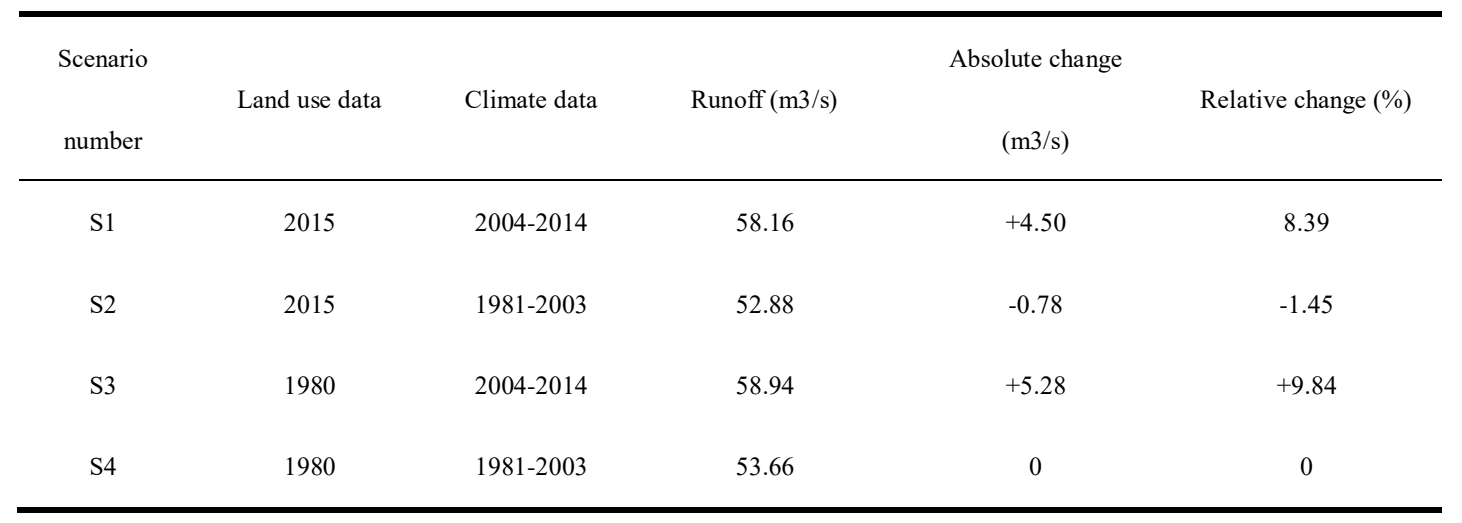

Table 1 Runoff simulation results under the influence of LUCC and climate change individually and jointly 


\section{Figures}
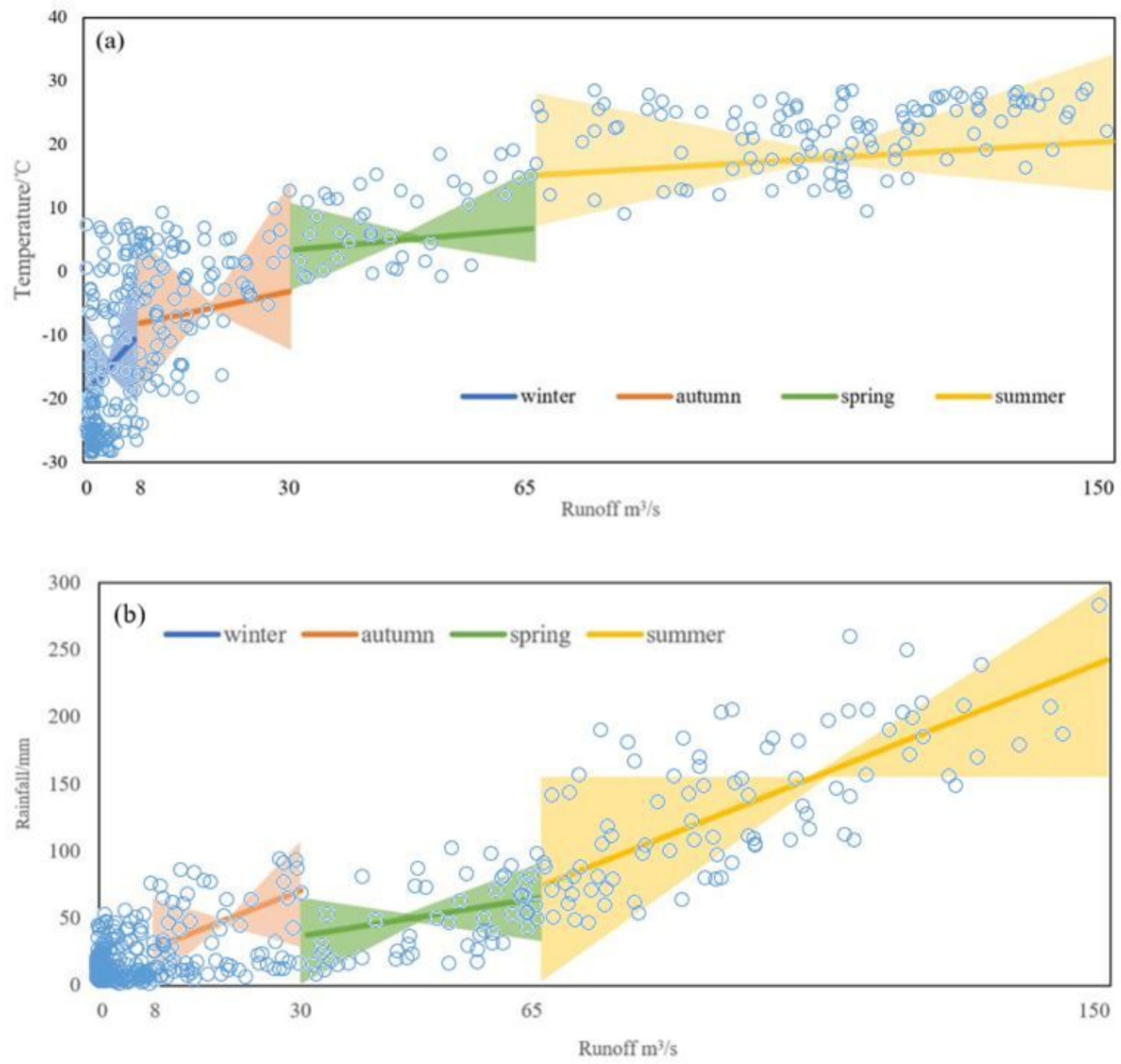

Figure 1

Correlation analysis of temperature(a),runoff(b) and rainfall. The slope of the four lines in Fig.1(a) represents the influence degree of temperature on runoff. The higher the slope is, the greater the influence degree of rainfall on runoff in that season is. The shadowed part in Fig.1(a) shows the distribution of temperature in that season. The slope of the four lines in Fig.1(b) represents the influence degree of rainfall on runoff. The higher the slope is, the greater the influence degree of rainfall on runoff in that season is. The shadowed part in Fig1. (b) shows the distribution of rainfall in that season. It should be 
noted that because the units of temperature and rainfall are different, the slopes between $a$ and $b$ cannot be compared.

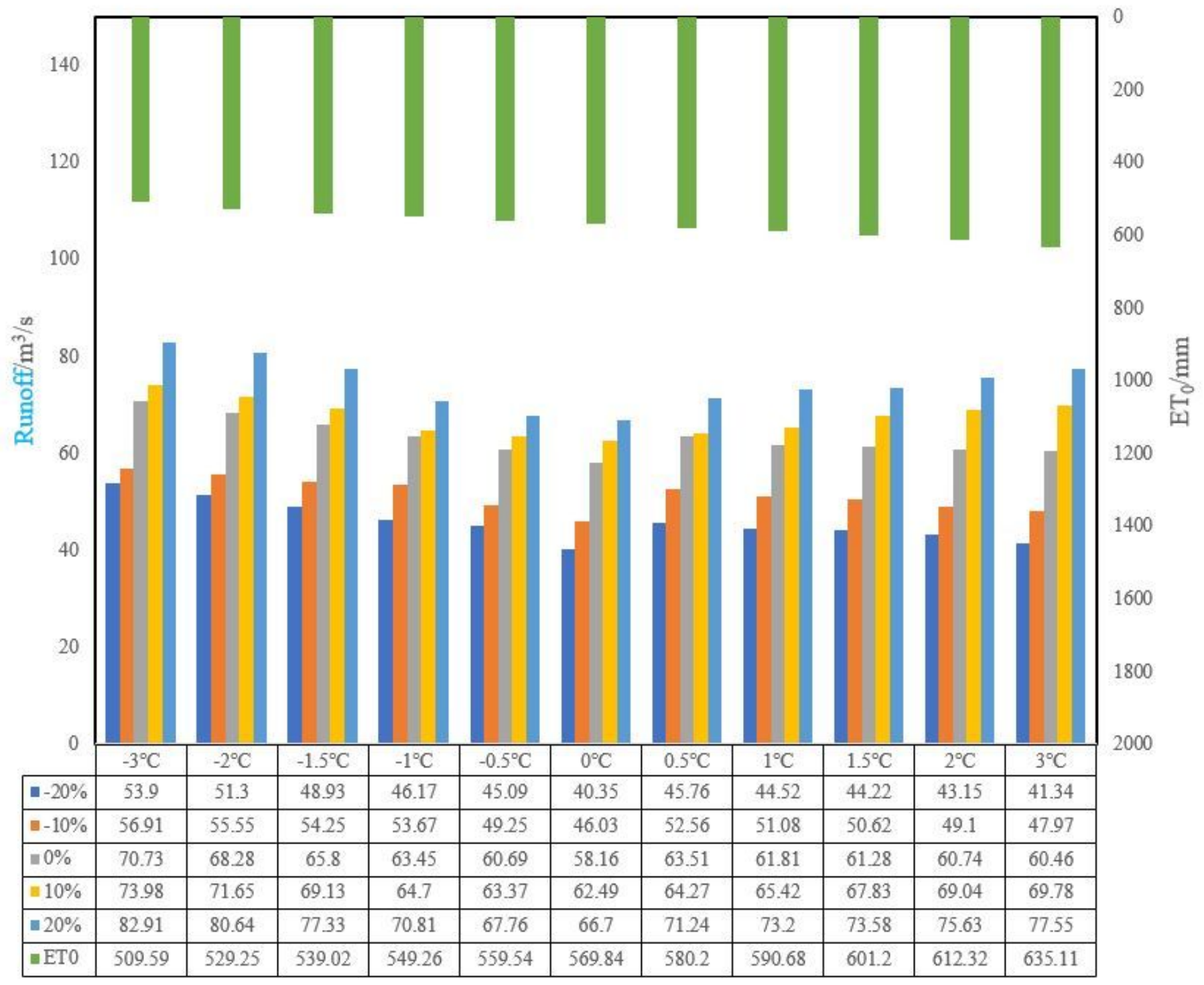

Figure 2

Runoff simulation results under combined change scenarios of temperature and rainfall 

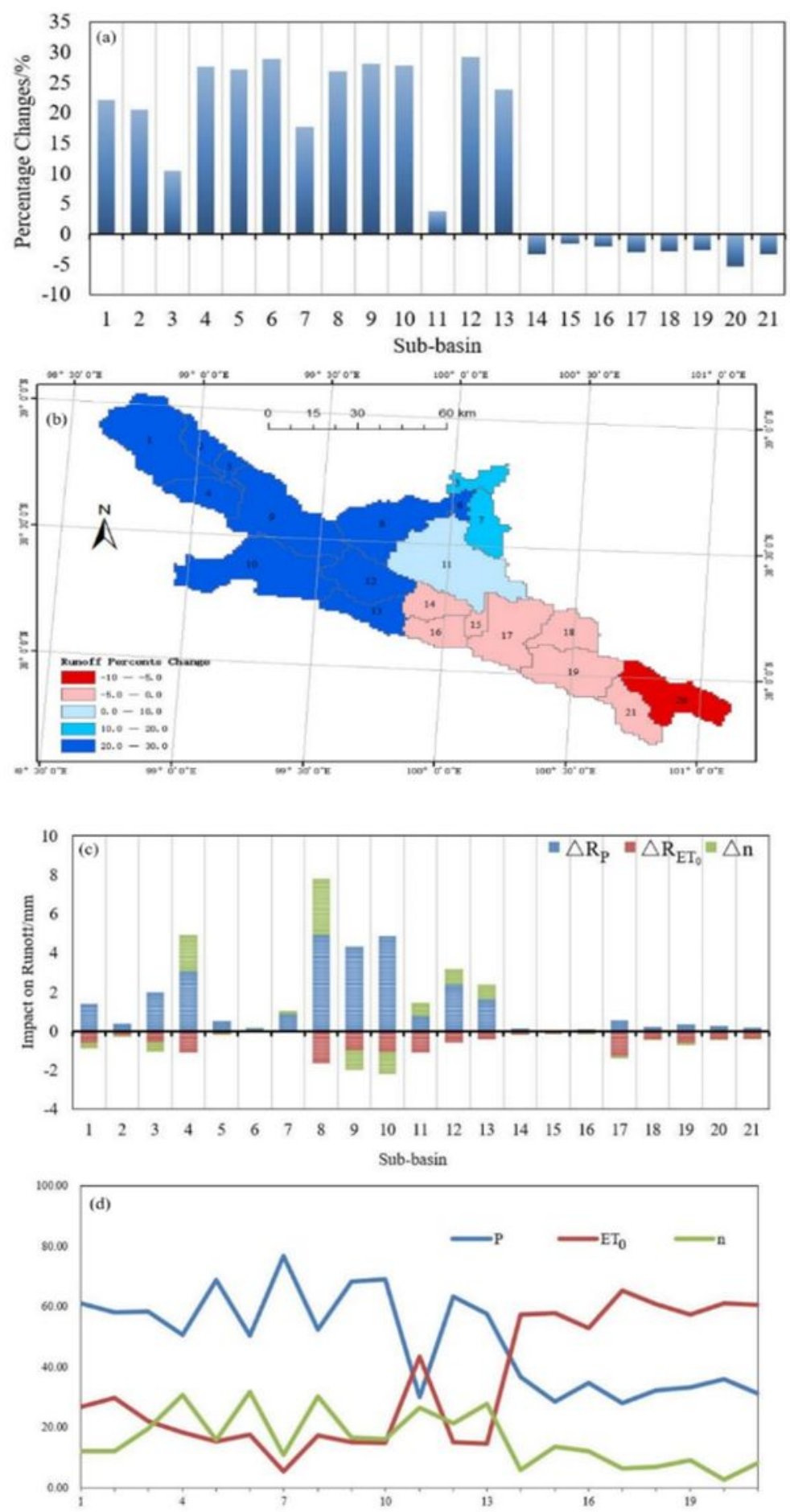

\section{Figure 3}

Runoff change and contribution rate of each factor in each sub-basin. Relative change rate of runoff in each sub-basin (a), spatial distribution of relative change rate of runoff (b), the response of each subbasin to each factor (c), the contribution rate of each factor to the runoff change of each sub-basin (d). Note: The designations employed and the presentation of the material on this map do not imply the expression of any opinion whatsoever on the part of Research Square concerning the legal status of any 
country, territory, city or area or of its authorities, or concerning the delimitation of its frontiers or boundaries. This map has been provided by the authors.
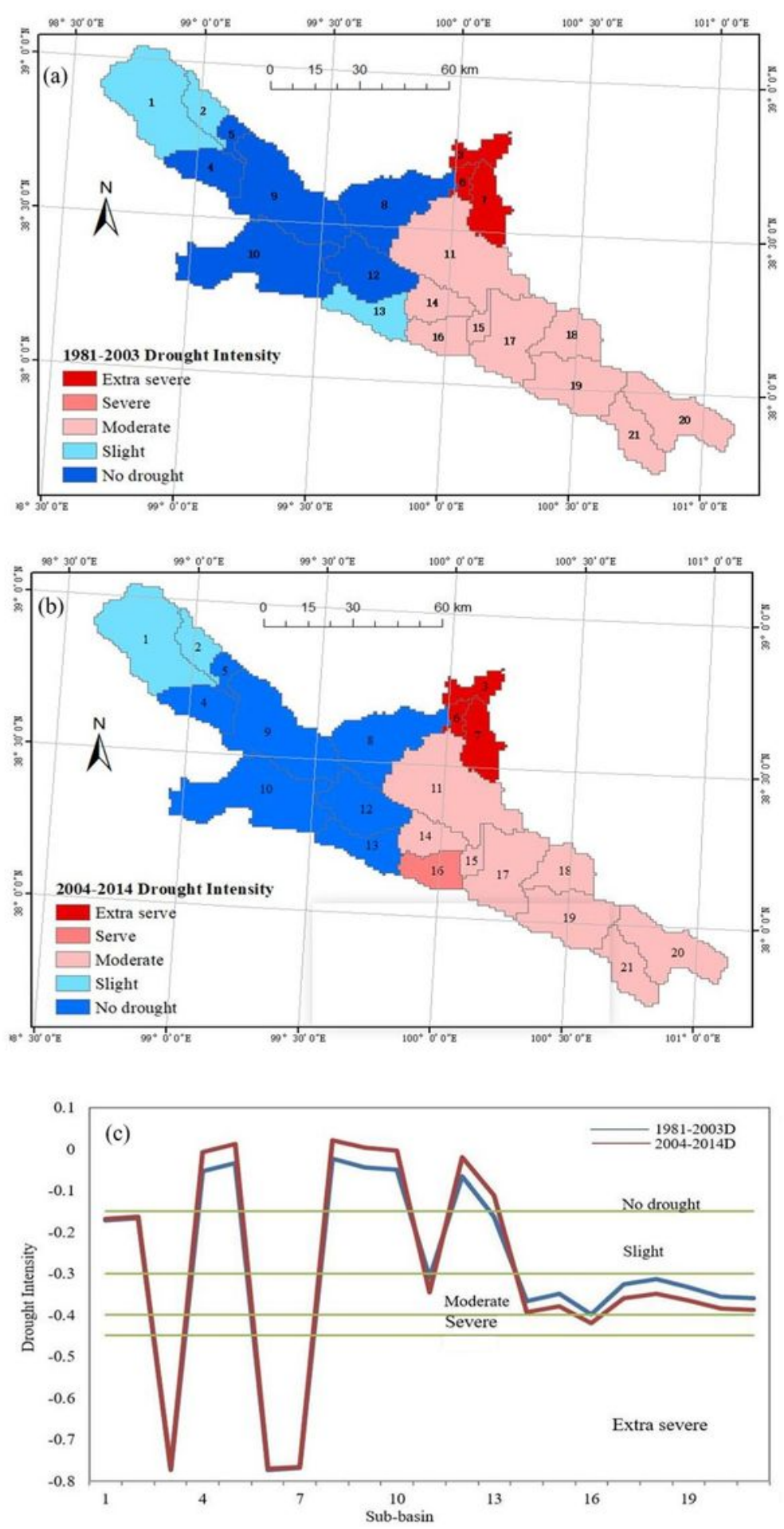

Figure 4

Spatiotemporal variation characteristics of $\mathrm{H}$ values. $\mathrm{H}$ values in each sub-basin from 1981 to 2003 (a), H values in each sub-basin from 2004 to 2014 (b), changes in $\mathrm{H}$ value in each sub-basin between 20042014 and 1981-2003 (c). Note: The designations employed and the presentation of the material on this 
map do not imply the expression of any opinion whatsoever on the part of Research Square concerning the legal status of any country, territory, city or area or of its authorities, or concerning the delimitation of its frontiers or boundaries. This map has been provided by the authors.

\section{Supplementary Files}

This is a list of supplementary files associated with this preprint. Click to download.

- Supplementarymaterial.pdf

- Tables.pdf 